\title{
Avaliação Nacional da Alfabetização no contexto escolar: um olhar para as concepções docentes e da gestão educacional
}

\section{National Literacy Evaluation in the school context: a view for teaching conceptions and educational management}

\section{Evaluación Nacional de Alfabetización en el contexto escolar: una morada para concepciones docentes y de gestión educacional}

Márcia Vânia Silvério Perfeito ${ }^{1}$

Solange Alves de Oliveira-Mendes ${ }^{1}$

Lucinalva Andrade Ataíde de Almeida²

\section{DOI: http://dx.doi.org/10.20435/serie-estudos.v24i51.1160}

\begin{abstract}
Resumo: Este estudo objetivou refletir sobre as implicações da Avaliação Nacional da Alfabetização (ANA) no cotidiano da prática alfabetizadora de duas professoras e de uma profissional da equipe gestora de uma Unidade de Ensino vinculada à Secretaria de Estado de Educação do Distrito Federal. A pesquisa está ancorada em Freitas (2005a, 2005b, 2007, 2012, 2016), Freitas et al. (2012), Luckesi (2011), Vázquez (1968) entre outros autores, por trazerem contribuições substanciais a este campo do conhecimento. Como técnica de investigação, foram realizadas entrevistas semiestruturadas no segundo semestre de 2017, direcionadas à gestora e às professoras alfabetizadoras que atuavam no 3o ano do Bloco Inicial de Alfabetização. Alguns temas foram priorizados, tais como: a importância (ou não) das avaliações externas para a aprendizagem dos estudantes e para o encaminhamento do trabalho em sala de aula e na escola, sentimento no momento de aplicação e diante do resultado da ANA; apropriação e análise dos resultados aferidos e utilização (ou não) desses índices para a organização do trabalho pedagógico. Os resultados realçaram como essa política educacional mantém a escola e os profissionais sob pressão, sobretudo a responsabilização que os sujeitos vêm sofrendo. Enquanto a gestora manifestou preocupação em elevar os índices, as alfabetizadoras, por outro lado, revelaram compromisso com uma análise mais pedagógica que dialogue com a construção heterogênea das aprendizagens.
\end{abstract}

\footnotetext{
${ }^{1}$ Universidade de Brasília (UNB), Brasília, Distrito Federal, Brasil.

${ }^{2}$ Universidade Federal de Pernambuco (UFPE), Recife, Pernambuco, Brasil
} 
Palavras-chave: Avaliação Nacional da Alfabetização; ensino de alfabetização; avaliação das e para as aprendizagens; organização do trabalho pedagógico.

Absctract: This study had as aim to reflect on the implications of the National Literacy Evaluation (ANA) in the daily practice for literacy by two teachers and a professional of the management team in a Teaching Unity linked to the State Secretary of Education of the Distrito Federal. The research is based on Freitas (2005a, 2005b, 2007, 2012, 2016), Freitas et al. (2012), Luckesi (2011), Vázquez (1968) and other authors as they bring substantial contributions to this knowledge field. As investigation techniques, semi structured interviews were carried out in 2017 second semester, addressed to the manager and to the literacy teachers who work with the $3^{\text {rd }}$ year of the Literacy Initial Block. Some themes were prioritized, such as the importance (or not) of external evaluations for students' learning and to classroom and at school work referrals, feelings at the moment of evaluation and before the results of ANA; appropriation and analysis of results gauged and use (or not) of these indexes to organize the pedagogical work. The results highlighted how this public policy maintains the school and the professionals under stress; especially the responsibility of subjects has suffered. While the manager expressed concern in lift the indexes, the literacy teachers, on the other hand, revealed commitment with a pedagogical analysis which dialogue with the heterogeneous construction of learning.

Keywords: Nacional Literacy Evaluation; literacy teaching; evaluation of and for learning; organization of pedagogical work.

Resumen: Este estudio tuvo el objetivo de reflejar sobre implicaciones de la Evaluación Nacional de Alfabetización (ANA) en el cotidiano de práctica alfabetizadora de dos profesoras y de una profesional del equipo gestora de una Unidad de Enseñanza encuadernada con la Secretaria de Estado de Educación del Distrito Federal. La investigación está anclada en Freitas (2005a, 2005b, 2007, 2012, 2016), Freitas et al. (2012), Luckesi (2011), Vázquez (1968) y otros autores, pues traen contribuciones substanciales para este campo del conocimiento. Cómo técnica de investigación, entrevistas semiestructuradas fueron realizadas en el segundo semestre de 2017, direccionadas a la gestora y las maestras alfabetizadoras que actuaban con el $3^{\text {er }}$ año del Bloque Inicial de Alfabetización. Algunos temas fueron explorados, tales como la importancia (o no) de las evaluaciones externas para el aprendizaje de los estudiantes y para el direccionamiento del trabajo en clase y en la escuela, sentimiento en el momento de aplicación y delante del resultado de la ANA; apropiación y análisis de los resultados medidos y utilización (o no) de esos índices para la organización del trabajo pedagógico. Los resultados despegaron como esta política pública mantiene la escuela y los profesionales bajo estrés, sobretodo la responsabilidad que los sujetos han sufriendo. Mientras la gestora manifestó preocupación en elevar los índices, las alfabetizadoras, por otro lado, revelaron compromiso con un análisis más pedagógico, que dialogue con la construcción heterogénea de aprendizajes.

Palabras clave: Evaluación Nacional de la Alfabetización; enseñanza de alfabetización; evaluación de y para el aprendizaje; organización del trabajo pedagógico. 


\section{INTRODUÇÃO}

No Brasil, a avaliação em larga escala, ou avaliação externa, teve início na década de 1990, com a criação do Sistema de Avaliação da Educação Básica (SAEB) pelo Instituto Nacional de Estudos e Pesquisas Educacionais Anísio Teixeira (INEP). Há mais de duas décadas, temos assistido a um crescimento dos exames regulares estaduais e nacionais que geram os indicadores de desempenho educacional para avaliar a qualidade do ensino no Brasil, justificadas com a finalidade de produzir informações para subsidiar a formulação e a reformulação das políticas públicas educacionais.

Para o Ministério da Educação (MEC), os resultados entregues a cada rede de educação e suas unidades de ensino, possibilitam a intervenção pedagógica; logo, não devem ser vistos como um ranking, mas, sim, como uma orientação para o trabalho pedagógico. Essa, entretanto, é a premissa oficial, não parece ser a apropriação que os docentes vêm realizando. O fato é que as escolas vêm sendo submetidas a constantes exames externos, elaborados, controlados, aplicados e corrigidos pelo Estado. Esse quadro tem implicações no trabalho docente e nas práticas tecidas no interior da escola.

Com o propósito de enfrentar os desafios postos à alfabetização e assegurar os direitos à aprendizagem básica em Língua Portuguesa e em Matemática dos estudantes matriculados no 3o ano do Ensino Fundamental, é que a Avaliação Nacional da Alfabetização (ANA) foi criada em 2013. A ANA, conforme o documento orientador (BRASIL, 2013), objetiva fazer um diagnóstico do processo de alfabetização.

Os sistemas de ensino, segundo Freitas (2005b), estão sendo disputados por propostas políticas e por diversas concepções educativas que usam e abusam da regulação. A regulação entendida aqui como ações decididas e executadas por uma instância superior para orientar as ações dos sujeitos sobre os quais se tem certa autoridade.

É nesse contexto que esse estudo se situa, visto que buscou analisar as implicações da ANA, em específico, no cotidiano de duas professoras alfabetizadoras e uma integrante da equipe gestora de uma instituição pública de ensino no Distrito Federal. Por meio da aplicação de entrevistas semiestruturadas, foi possível conhecer como acontecia, no interior de uma unidade de ensino (UE), a 
apropriação, a análise e a divulgação dos resultados aferidos pela ANA e como a escola organizava seu trabalho pedagógico com vistas à qualidade dos processos de ensino e de aprendizagem na alfabetização.

Seguimos explicitando nosso quadro teórico, assim como a discussão dos dados aqui produzidos. Tecemos, inicialmente, considerações sobre a ANA; em seguida, esclarecemos nossas opções metodológicas. Posteriormente, articulamos os dados produzidos com a literatura eleita para o diálogo. Por fim, apresentamos nossas reflexões finais.

\section{ALGUMAS CONSIDERAÇÕES SOBRE A ANA}

A avaliação está vinculada ao ensino, aos objetivos educacionais que se concretizam na escola e na sala de aula. Esse processo pode ser marcado pelo princípio da continuidade, da progressão das aprendizagens, no caso de uma avaliação formativa, ou, ao contrário, ser pontual, estático, não articulado, como se configura a avaliação somativa. Enquanto aquela compreende que a construção do conhecimento é processual e não defende a comparação entre os sujeitos; a segunda, na contramão, é realizada de forma pontual e numa escala de somas, não de progressão, ou seja, não entende que o processo atual está acoplado ao anterior, conforme atesta Luckesi (2011).

Dessa forma, ao falarmos em avaliação externa, entendemos, de acordo com Luckesi (2011), que não se enfatiza o processo, mas uma medição que não ultrapassa um modelo uniforme de comparar os resultados entre as unidades de ensino o que, inevitavelmente, contribui para uma competitividade entre as escolas e redes de ensino. Em se tratando da ANA, sublinhamos que é um dos instrumentos do sistema de avaliação da Educação Básica (SAEB) e tem como finalidade aferir os níveis de alfabetização e letramento em língua portuguesa, alfabetização em matemática e as condições de oferta do ciclo de alfabetização das redes públicas. É uma avaliação censitária, na qual todas as escolas e alunos matriculados no 3 으 ano do Ensino Fundamental das instituições públicas são avaliados.

As provas são divididas em dois dias e começam pela área de Língua Portuguesa. São 20 questões desse campo do conhecimento e 20 de matemática. No caso de Língua Portuguesa, o teste é composto de 17 itens objetivos de múltipla escolha e três itens de produção escrita. No caso de Matemática, 20 itens 
objetivos de múltipla escolha. A ANA avalia o início da aprendizagem da norma ortográfica e o domínio progressivo da escrita, por meio de três questões abertas, compostas pela escrita de duas palavras de estruturas silábicas diferentes e uma pequena produção textual. Com a produção textual, avaliam-se os contextos de uso da escrita, a organização textual, a coerência e coesão da produção, o uso de pontuação, aspectos ortográficos e gramaticais.

A primeira versão foi aplicada em 2013; a segunda, em 2014; e a terceira edição, em 2016. A ANA, quando iniciada, vinculava-se ao programa de formação continuada, ação integrante do Pacto Nacional pela Alfabetização na Idade Certa (PNAIC), instituído pela Portaria n. 867, de 4 de julho de 2012 (BRASIL, 2012), um compromisso firmado pelos governos federal, estadual, Distrito Federal e administrações municipais, cuja meta central era a de assegurar que todas as crianças estivessem alfabetizadas aos oito anos de idade, ou seja, até o fim do 3 o ano do Ensino Fundamental. Ainda que essa meta tenha sido alterada pela Base Nacional Comum Curricular (BNCC), que prevê a alfabetização nos dois primeiros anos do Ensino Fundamental (BRASIL, 2017b), isso coaduna com a ideia dessa política de formação estar atrelada à busca por melhores resultados nas avaliações em larga escala, nesse caso, a ANA.

A primeira avaliação objetivou oferecer um parâmetro capaz de permitir análises posteriores. A avaliação aplicada em 2014, segundo informações do MEC, apresentou a necessidade de o país evoluir nos índices de alfabetização. Os que foram divulgados em 2017 pelo INEP, relativos a 2016, demonstraram uma estagnação em relação aos de 2014. Revelaram que parte considerável dos estudantes, mesmo tendo passado pelos três anos de escolarização, ainda apresentavam níveis insuficientes de proficiência para a idade (BRASIL, 2017a).

Com o objetivo de combater essa estagnação, o Ministério da Educação (MEC) lançou, no dia 25 de outubro do ano de 2017, uma nova política, a Política Nacional de Alfabetização. Essa representa, de acordo com o MEC, um conjunto de iniciativas que envolvem a Base Nacional Comum Curricular (BNCC), a formação de professores, o protagonismo das redes e o Programa Nacional do Livro Didático (PNLD). Nessa mesma data, foi divulgada a criação do Programa Mais Alfabetização, o qual pretende atender estudantes com a presença de assistentes de alfabetização, que desenvolverão trabalho em conjunto com os alfabetizadores que atuam em turmas de 10 e 2 o anos do Ensino Fundamental. 
De acordo com o MEC, aos assistentes de alfabetização compete assistir ao professor alfabetizador no turno regular, por um período de cinco horas semanais para unidades escolares não vulneráveis, ou de dez horas semanais para as unidades escolares vulneráveis. Esses assistentes devem auxiliar as atividades estabelecidas e planejadas pelo professor alfabetizador.

Foram estabelecidos critérios para as unidades escolares vulneráveis:

I-em que mais de $50 \%$ dos estudantes participantes do SAEB/ANA tenham obtido resultados em níveis insuficientes nas três áreas da referida avaliação (leitura, escrita e matemática); e

II - que apresentarem Índice de Nível socioeconômico muito baixo, baixo, médio baixo e médio, segundo a classificação do Instituto Nacional de Estudos e Pesquisas Educacionais Anísio Teixeira - INEP (BRASIL, 2018, p. 5).

Ao declarar um conjunto de ações, ficou estabelecido que o MEC determinasse regras para a seleção do assistente de alfabetização, deixando Estados, Municípios e o Distrito Federal responsáveis em garantir a realização de processo seletivo simplificado, bem como a qualificação desses. A Secretaria de Estado de Educação do Distrito Federal (SEEDF) definiu um perfil para esses auxiliares e critérios para sua seleção: ser brasileiro; ter a idade mínima de 18 (dezoito) anos no ato da inscrição; Graduados em Pedagogia ou outra licenciatura e/ou estar, no mínimo, cursando Pedagogia ou outro curso de licenciatura.

Para Freitas (2005a), o par dialético objetivos/avaliação é a categoria para compreensão da organização do trabalho pedagógico da escola capitalista, visto que essa incorpora os objetivos da sociedade. Ao se remeter à avaliação externa como fator que aumenta o controle sobre a escola e a população escolarizável, o autor garante que essa categoria precisa ser analisada a partir de dois níveis:

[...] seus efeitos no interior da sala de aula e da escola como um todo, através do Projeto Político- Pedagógico, uma vez que existe uma tendência para que a função social atribuída à escola capitalista seja retransmitida à escola ao procurar controlar as ações em seu interior e no interior da sala de aula, em meio a tensões, resistências e contradições existentes na disputa pelo controle técnico/político. (FREITAS, 2005a, p. 143).

Assim, os exames externos controlam o aparelho educacional e a própria avaliação interna. Ao dizer isso, destaca a influência do modo de produção capitalista na escola e como a avaliação vem determinando o próprio trabalho pedagógico, 
como se dele não fosse uma categoria, mas, sim, algo maior, estruturando as demais como o planejamento, o método e o conteúdo (FREITAS, 2016).

Nesse caso, o magistério está fundamentalmente marcado pelo controle, o que leva a uma crescente desprofissionalização da categoria. Nesse texto, embora conhecida como avaliação externa, nossa compreensão é a de que se constitui, na realidade, como exame. Esses exames, ao instituírem indicadores para medir performances dos alunos, das escolas e de seus professores, legitimam o controle do trabalho docente.

Para Gatti (2012), as avaliações em larga escala ao serem adotadas como a grande política e currículo educacional, contribuem para definir a equidade social. Os trabalhadores docentes estão inseridos no sistema educacional que reflete a organização do modo de produção capitalista e tende à perpetuação da dicotomia entre os que pensam e aqueles que executam.

De acordo com Hypólito (1991, p. 17), “[...] o processo de dominação e controle sobre o trabalho não se dá somente no que se refere ao conteúdo do ensino, mas também sobre as formas de transmissão desse conteúdo". Portanto dificultam a efetivação da autonomia da escola e o processo de descentralização, tornando o trabalho do professor alienado, distorcendo-o do verdadeiro sentido do trabalho como categoria fundante do ser social, mediante a transformação do meio e de si mesmo. Na visão de Marx (1964), ocorre a coisificação do homem em relação ao produto do seu trabalho, isto é, a alienação da coisa, do objeto, do produto do seu trabalho, o que o leva à proletarização.

Para Magalhães et al. (2018, p. 96), "na atualidade, os discursos em torno da avaliação revelam resquícios de sua memória discursiva, posto ainda orientar-se por efeitos de sentidos aparentemente esquecidos e apagados na história, como a avaliação enquanto medida, descrição e formulação de juízos de valor".

Entretanto o que se busca é alcançar um conceito de avaliação formativa, cuja concepção pressupõe uma mudança no ato de avaliar. Nessa ótica, é preciso debruçar-se sobre os dados produzidos pelas avaliações, buscando imputar-lhes um proveito expressivo na prática docente. A utilização e a diversificação de instrumentos de avaliação podem colaborar para uma melhor compreensão das diferentes realidades encontradas no contexto escolar.

Passemos, após essa sistematização, a apresentar nossas escolhas e procedimentos metodológicos que orientaram o desenvolvimento desse estudo. 


\section{METODOLOGIA}

A partir de uma abordagem qualitativa de pesquisa e com vistas à contextualização do objeto investigativo, a Avaliação Nacional da Alfabetização (ANA), objetivamos alcançar implicações dessa política externa de avaliação na prática de duas alfabetizadoras que atuavam no 3 ㅇa ano do Bloco Inicial de Alfabetização (BIA) em 2017 e representante da equipe gestora de uma Unidade de Ensino vinculada à Secretaria de Estado de Educação do Distrito Federal (SEEDF), pertencente à Coordenação Regional de Ensino da cidade do Recanto das Emas.

As entrevistadas tinham longa atuação no magistério na Secretaria, aproximadamente 20 anos com alfabetização de crianças. Possuíam formação inicial em Pedagogia e definiam o ato de avaliar como necessário para diagnosticar, diariamente, as aprendizagens dos estudantes, objetivando o (re) planejamento da prática docente.

Optamos por realizar entrevistas semiestruturadas, a fim de apreender as concepções das profissionais acerca daquela política. As entrevistas foram conduzidas no segundo semestre de 2017. Para Gil (1999), a entrevista é seguramente a mais flexível de todas as técnicas de coleta de dados de que dispõem as ciências sociais.

Interessamo-nos por analisar de que modo esses exames externos controlavam o aparelho educacional, determinando o que e o como ensinar. Para tanto, elegemos alguns temas que nortearam a entrevista e a análise nesse texto: importância (ou não) das avaliações externas para a aprendizagem dos estudantes e para o encaminhamento do trabalho em sala de aula e na escola; sentimento no momento de aplicação e diante do resultado da ANA; apropriação e análise dos resultados aferidos; utilização (ou não) desses índices para a organização do trabalho pedagógico. As questões foram essencialmente as mesmas tanto para a gestora, quanto para as professoras.

Com isso, esse ensaio permitiu a reflexão sobre como a ANA pode influenciar a prática pedagógica de alfabetizadoras e equipe gestora, instituindo novas relações desses profissionais com o processo pedagógico. Partindo dessas considerações, na próxima seção, apresentamos a análise de como a equipe da Unidade de Ensino concebia e/ou percebia a avaliação da/para as aprendizagens, os exames externos, bem como a qualidade do ensino na alfabetização. 


\section{RESULTADOS E DISCUSSÕES}

\subsection{A avaliação externa na percepção das professoras}

Quanto à importância (ou não) das avaliações externas para a aprendizagem dos estudantes e para o encaminhamento do trabalho em sala de aula e na escola, as entrevistadas consideraram-nas relevantes por apontarem indicativos para o trabalho escolar e por provocarem mudanças de atitudes em relação às práticas pedagógicas, todavia, para as professoras, a avaliação realizada em sala de aula era a que direcionava a ação pedagógica. Vejamos o que sublinharam:

[...] em sala de aula, tudo se torna passível de avaliação. É uma avaliação formativa. Dentro da sala de aula, existem muitos mecanismos para avaliar. A avaliação em sala de aula é o que direciona a ação, mostra as falhas, os erros, o que precisa ser modificado para gerar aprendizagem significativa. Avaliar representa uma resposta, um retorno do que está sendo feito. Qualquer mudança relacionada ao trabalho é avaliar. (ALFABETIZADORA 1- 3o ano).

[...] Quando não sabemos onde houve necessidade, é difícil de trabalhar as questões. Acaba por agir em decorrência do que se observa em sala de aula. Trabalhamos as necessidades no decorrer do processo. É no dia a dia que podemos perceber em que o aluno precisa melhorar. (ALFABETIZADORA 2- 3ㅇano).

Podemos inferir que, ao considerarem a avaliação inseparável da prática pedagógica, o tema não parecia desconhecido das professoras, pelo contrário, demonstravam praticá-la no processo de ensino e de aprendizagem. Reconheciam a avaliação formativa como uma alternativa didática capaz de permitir a reflexão das ações desenvolvidas pelos sujeitos em sala de aula. A avaliação das e para as aprendizagens integrava, portanto, o trabalho docente.

O diálogo intrínseco entre a avaliação formativa e as avaliações externas é imprescindível, entretanto estudos como o de Magalhães (2018) denunciam o descompasso entre a prática de sala de aula e os mecanismos externos de avaliação. Nesse estudo, ficaram evidentes, entre outros aspectos, determinismos externos nas práticas de sala de aula, alcançando, inclusive, modificações no trato com os objetos de saber, ou seja, conteúdos que estavam sendo antecipados em função das cobranças nas avaliações. 
Freitas (2005b), ao se referir à política de avaliações externas, esclarece que os processos de medição de desempenho dos alunos devem ser recolocados em seu devido lugar, como parte de um conjunto mais amplo de informações da realidade das escolas, favorecendo a reflexão e a organização dos trabalhadores em cada uma delas.

Para o autor, a qualidade deve ser produto de um processo de avaliação institucional construído coletivamente, tendo como referência o projeto político- pedagógico da escola, entretanto as avaliações de larga escala vêm se constituindo em referência principal para a avaliação da qualidade de ensino no Brasil e em muitos outros países. Realizam-se estas para avaliar não só o que as crianças e jovens aprendem nas escolas, mas como e com que conteúdos os professores vêm trabalhando (FREITAS, 2012). Esse engessamento e precarização do trabalho docente, ressaltamos, também é evidenciado no estudo realizado por Magalhães (2018).

Com base nas falas das professoras, foi possível perceber a preocupação com os resultados das avaliações externas e o clima de tensão ou ansiedade por um melhor desempenho. Segundo as profissionais, o Índice de Desenvolvimento da Educação Básica (IDEB) da escola caiu em relação ao ano de 2015. Prossigamos em apreender o que enfatizaram, incluindo a compreensão da gestora:

As avaliações externas oferecem indicativos para o trabalho da escola, noção de como a escola está e o nivel das crianças diante das aprendizagens. Evitam a acomodação e possibilita ver como está a condução do trabalho na escola. Temos noção de como a criança está chegando ao 3o ano. Se está alfabetizada ou não. Esse ano o IDEB da escola baixou e a gente se preocupou... (GESTORA).

[...] os resultados da escola já foram melhores, mais expressivos que os atuais. Muitas crianças não vão corresponder ao que foi esperado por diferentes fatores. Às vezes, a resposta não é tão satisfatória. (ALFABETIZADORA 1- 3응 ano).

Entendemos que a implantação das avaliações externas modificou o cotidiano profissional, produzindo novas demandas para os gestores e para os professores. Por vezes corroboraram para aumentar a angústia e a frustração da equipe, ao ponto de se responsabilizarem, sozinhas, pelo resultado, retirando o foco do Estado em relação às condições de trabalho. 
As narrativas das profissionais pareceram influenciadas pelo lugar que ocupam, ou seja, pela função que desenvolvem. Para os gestores, suas funções estão diretamente relacionadas à promoção do diálogo entre as políticas educacionais e o cotidiano escolar, ou seja, sua função não permite uma postura de negação radical das avaliações externas. Isso pode explicar a preocupação da gestora com a política de avaliação externa ao se sentir pressionada a apresentar resultados mais satisfatórios.

Já a professora, ao falar do lugar em que ocupa, expressa as especificidades do cotidiano, nas avaliações diárias realizadas em sala de aula, acompanha, intervém quando necessário, ao passo que, na avaliação externa, por vezes, o que é exigido dos estudantes não coincide com o ensinado, fazendo com que eles se sintam alheios frente ao instrumento.

Enquanto a gestora relatou que os exames contribuíam para orientar o processo de aprendizagem e desenvolvimento dos estudantes, as docentes, por sua vez, relataram que se sentiam ansiosas nos momentos de aplicações da ANA. Vejamos o que apontaram:

O sentimento é de um vestibular, pois essas avaliações são diferentes das realizadas em sala de aula. Os estudantes não conseguem demonstrar tudo o que sabem [...] a resposta não é satisfatória. (ALFABETIZADORA 2-3ำ ano).

Com as professoras, eles vão mostrando aos poucos os conhecimentos adquiridos, por meio de diversos instrumentos utilizados. (ALFABETIZADORA 1-3ㅇano).

As professoras destacaram, nesse trecho, o fato de que, embora estivessem presentes em sala de aula no momento da aplicação, não poderiam colaborar com esta, a não ser com a questão disciplinar, porque, para os exames externos, existiam aplicadores treinados que, por vezes, podiam intimidar os estudantes. Importa ressaltar que professor e estudantes criam uma relação afetiva em sala de aula, conferindo maior confiança e segurança para as crianças.

Os exames externos tornam-se preocupantes à medida que os resultados quantitativos ganham destaque. Geram situações em que os desempenhos, focados nos resultados aferidos, desconsideram os processos e colocam as instituições em evidência pelos índices. Cabe provocar uma reflexão: se o desempenho dos estudantes indica a qualidade da educação oferecida pela Unidade de Ensino, a quem cabe a responsabilidade pela aprendizagem dos conhecimentos escolares? 
As duas alfabetizadoras, ao se referirem ao próprio trabalho, consideraram-no como base, alicerce para um bom desenvolvimento escolar do estudante, por ser, a alfabetização, um período importante, exigia delas dedicação na tentativa de fazer sempre o melhor.

Seguimos com a discussão dos dados, destacando como ocorria, no cotidiano pesquisado, o conhecimento, a análise e/ou interpretação dos resultados e a utilização (ou não) desses índices para a (re) organização do trabalho pedagógico.

\subsection{A apropriação e análise dos resultados aferidos pela ANA na percepção das professoras}

O documento base da ANA a define como um instrumento diagnóstico da situação escolar dos alunos (BRASIL, 2013). É decisivo refletir sobre essa lógica classificatória e sobre certas questões quando existe o desejo por uma aprendizagem significativa dos estudantes alfabetizandos, na qual 'rotular', 'classificar', 'constranger' e 'punir' não fazem parte da defesa da qualidade do sistema público de educação.

Sobre a apropriação, divulgação e análise dos resultados aferidos pela ANA, a equipe gestora os fazia durante as coordenações pedagógicas coletivas com todos os professores, por meio de gráficos e estudos sobre a matriz de referência. Essas coordenações são momentos destinados à formação continuada, ao planejamento, à avaliação dos trabalhos pedagógicos e ao atendimento às necessidades de aprendizagem dos estudantes. Para tanto, os professores da rede pública de ensino do Distrito Federal dispõem de carga horária de 15h semanais. Concretiza-se isso por meio das ações coletivas e individuais e pelas intencionalidades pedagógicas declaradas no Projeto Político Pedagógico das unidades escolares (DISTRITO FEDERAL, 2014).

A entrevistada apontou, também, que a orientadora educacional da Unidade Escolar desenvolvia papel importante nessa discussão e análise. Ao início de cada ano letivo, procurava pontuar, com o grupo de docentes, os avanços e os retrocessos enfrentados pelos estudantes, o que permitia traçar ações interventivas buscando dar continuidade aos processos de aprendizagem por meio das estratégias de reagrupamentos e projeto interventivo. Essas são ancoradas em princípios teórico-metodológicos, que objetivam atender aos estudantes em suas necessidades pontuais de aprendizagem durante o ano letivo. 
O Reagrupamento é uma estratégia de trabalho em grupo, que atende a todos os estudantes, permitindo o avanço contínuo das aprendizagens. Para Villas Boas (2013), o reagrupamento permite a interação com os estudantes que, em determinados momentos, realizam as mesmas atividades e em outros, as atividades são diferenciadas, apresentando desafios específicos. De acordo com a autora, essa alternativa didática é orientada pela avaliação diagnóstica das necessidades de aprendizagem.

O Projeto Interventivo parte de um diagnóstico e consiste no atendimento imediato aos estudantes que, após experimentarem todas as estratégias pedagógicas desenvolvidas nas aulas, ainda evidenciem dificuldades de aprendizagem. De acordo com Villas Boas (2010), os "projetos interventivos devem ser muito bem organizados para que nenhum estudante se perca. O professor observa, identifica e analisa as conquistas de cada estudante para orientar a continuidade da sua aprendizagem e do trabalho pedagógico" (VILLAS BOAS, 2010, p. 152). Para a pesquisadora, esse processo é a avaliação formativa em ação.

Reportando-nos à Avaliação Nacional da Alfabetização, Adrião e Borghi (2008, p. 910) ressaltam que a divulgação dos resultados da avaliação externa "tem servido como mecanismo de indução e alteração de práticas educativas no cotidiano da escola". Portanto é oportuno salientar que é preciso cuidar para não direcionar o ensino, exclusivamente, às competências avaliadas externamente, o que pode não corresponder às necessidades dos estudantes.

Nesse sentido, Paro (2008, p. 80-1) acrescenta que

[...] a preocupação com o provimento de um ensino de qualidade para a educação deve priorizar formas eficazes de se proceder à avaliação do processo escolar. [...] É preciso prever instrumentos institucionais que avaliem não apenas o rendimento do aluno, mas o próprio processo escolar como um todo.

Por outro lado, a avaliação institucional, prevista nas Diretrizes de Avaliação da SEEDF (DISTRITO FEDERAL, 2014-2016), tem como referência os objetivos prescritos no Projeto Político-Pedagógico. Ao avaliar todas as instâncias que compõem a organização escolar, é possível estabelecer metas com o intuito de colocar quaisquer ações a serviço das aprendizagens, inclusive auxiliando a reflexão sobre os dados oriundos da escola e dos exames externos.

Freitas (2007) corrobora com essa ideia, admite haver problemas nas escolas, porém é necessário reconhecer que não são menores nas políticas públicas 
e no sistema socioeconômico. Portanto Bondioli (2004) sugere uma parceria entre escola e governos com vistas à qualidade negociada por meio da avaliação institucional.

As docentes relataram que a equipe gestora e coordenadoras pedagógicas nem sempre discutiam e procediam à análise da ANA com o coletivo de professores. Apenas expunham os resultados, não existindo uma reflexão sobre esses indicadores a partir das matrizes de referência. Essas matrizes retratam a opção por determinados saberes e eixos. No contexto das avaliações em larga escala, são utilizadas para indicar habilidades a serem avaliadas em cada etapa da escolarização e orientar a elaboração de itens de testes e provas.

Além disso, também indica a construção de escalas de proficiência que definem o que e o quanto o aluno realiza no contexto da avaliação. Contribuem para organizar e categorizar habilidades relacionadas a determinado tipo de conteúdo ou conhecimento, que são, então, agrupados em subcompetências, tópicos, entre outros. Entretanto não esgotam o conteúdo a ser trabalhado em sala de aula e, portanto, não podem ser confundidas com propostas curriculares, estratégias de ensino ou diretrizes pedagógicas. O uso dessas matrizes pode envolver riscos para o currículo escolar.

Assim, efeitos são sentidos no âmbito do currículo e do trabalho que é desenvolvido na escola: empobrecimento de conhecimentos, restritos às competências básicas e empobrecimento do ensino que se condiciona "ao que é cobrado nos exames", direcionando o trabalho na sala de aula com características de treinamento para os exames. (ARAújO, 2012, p. 4).

As alfabetizadoras convergiram ao dizer que, quando a análise acontecia, era por meio do Centro de Referência para os Anos Iniciais (CRAI), equipe da Coordenação Regional de Ensino (CRE), os quais atuam na formação continuada dos profissionais que trabalham nessa etapa da Educação Básica. Ambas consideravam imprescindível a discussão e análise durante as coordenações pedagógicas sob o direcionamento da equipe gestora e coordenação pedagógica da instituição.

Ao mesmo tempo em que demonstraram sentimentos de ansiedade, angústias e frustrações, as docentes acreditavam na avaliação externa como impulsionadora da melhoria da prática cotidiana em sala de aula e para implementação de cursos de formação continuada. Para a alfabetizadora 1, a equipe gestora, ao 
expor os resultados em momentos de reuniões na escola, fazia-o "como cobrança, para dar uma sacudida na equipe escolar".

Conforme Freitas (2012), o caminho dos números tem destruído a relação entre as pessoas nas escolas, instaurando a competição, e não um trabalho colaborativo. Portanto, ao divulgar os resultados, há que se ter prudência.

Ao se referirem aos resultados da escola, a alfabetizadora 1 os atribuiu à inexistência de articulação entre teoria e prática. Para ela, os professores de hoje têm muita teoria e pouca prática, uma vez que a teoria permite àqueles profissionais refletirem sobre sua atividade e reconstruí-la, mas, por outro lado, denunciaram que alguns profissionais chegavam às escolas sem saber como ensinar. Mais uma vez, pairava uma cobrança no perfil do profissional em função das avaliações externas.

Há, de forma notória, um impacto direto entre a prática cotidiana e o exame (MAGALHÃES, 2018). Por meio da ação-reflexão-ação, é que os docentes poderão dar conta da superação dicotômica entre teoria e prática, marca da racionalidade técnica, que tem raízes históricas no positivismo e ignora a criatividade do professor, fazendo dele apenas um executor de programas e/ou projetos estabelecidos e concebidos por especialistas ou acadêmicos. A reflexão sobre o que fazemos diariamente em nosso trabalho para melhorá-lo chamamos de práxis, a união da teoria com a prática, conforme atesta Vázquez (1968).

Para a professora 2, o problema estava na organização escolar em ciclos. Segundo ela, deixava a família omissa e contribuía para que muitos estudantes chegassem ao final do 3ㅇa ano sem conhecimentos satisfatórios para consolidar o processo de alfabetização, por isso, repetiam duas ou três vezes o último ano do Bloco Inicial de Alfabetização (BIA), como era denominado no Distrito Federal, etapa em que era permitida a retenção. O primeiro bloco da organização escolar em ciclos, que correspondia aos 1으, 2으 e 30 anos do Ensino Fundamental, implantado em 2005 e ampliado em 2008 para toda a rede pública.

Enquanto não houver, afirma Lüdke (2001), uma articulação dos pressupostos defendidos no ciclo, tais como: flexibilização curricular, progressão dos saberes, formação docente, entre outros, o ciclo continuará sendo apontado como vilão responsável pelo fracasso escolar. O estudo realizado por Oliveira (2010) sublinha que a ausência de uma proposta curricular que clarifique as competências para cada ano estava desembocando em perfis discrepantes ao término do ciclo da 
alfabetização. Na ocasião, as professoras que contribuíram com a pesquisa, afirmavam que faltava clareza da equipe de formação quanto à operacionalização dos ciclos de aprendizagem, na prática.

Em relação aos ciclos, em estudo realizado, Pereira (2015, p. 34) sinaliza que "[...] o BIA tem resistido, o que reforça nossa crença na organização da escola em ciclos como uma alternativa capaz de driblar as instabilidades do cenário político". Mainardes (2009) enfatiza que os ciclos pretendem superar o modelo da escola graduada, organizada em séries anuais, o que exige mudanças significativas na estrutura das escolas como um todo e nas formas de conduzir as aprendizagens em sala de aula.

Para Arroyo (1999) a lógica seriada, na maioria das escolas, não é alterada, por vezes é até reforçada, assim, apenas o fluxo escolar é amenizado com mecanismos de não reprovação, de aceleração ou de adiamento da retenção.

Pereira (2015) converge com os autores supracitados ao observar que ampliar o tempo e reorganizar os espaços no BIA não garante as aprendizagens

[...] é necessário que outras intervenções sejam desenvolvidas em conjunto com essas medidas, a fim de garantir que o BIA se estabeleça como uma escola diferente da que conhecemos tão bem. Além disso, é essencial que todos os envolvidos no processo educativo possam discutir, estudar e refletir sobre os pressupostos da escola organizada em ciclos e, especialmente, sobre o conceito e a concepção de progressão continuada das aprendizagens. (PEREIRA, 2015, p. 40).

Isso nos leva a refletir que esse tipo de organização exige mudanças na escola e nas práticas pedagógicas, buscando assegurar a progressão das aprendizagens. Ressaltamos, para isso, a importância da apropriação dos conteúdos, bem como um significativo investimento no planejamento das aulas e uma avaliação pautada na e para as aprendizagens.

Todavia a ANA pode contribuir com as práticas avaliativas desenvolvidas pela UE quando ancoradas, entre outros aspectos, na proposta curricular. O objetivo é aproximar e não criar abismos entre as práticas escolares e os exames externos. À medida que não fiquem restritos à medição, esses exames podem oferecer caminhos, juntamente com outros instrumentos, para a efetivação do direito de aprendizagem de todos os aprendizes. 


\section{CONSIDERAÇÕES FINAIS}

A discussão sobre a qualidade da educação vai além dos resultados de aprendizagem medidos por testes provenientes dos sistemas de avaliação em larga escala. A qualidade do ensino está relacionada ao trabalho desenvolvido no cotidiano da escola. A equipe da UE precisa buscar caminhos para organizar-se e lidar com a avaliação externa visando à melhoria das aprendizagens e da qualidade do ensino sem preocupações, apenas, com os resultados quantitativos. Para tanto o diálogo entre os exames externos e o que é ensinado em sala de aula estreitaria essa relação e não tornaria os estudantes "estranhos" ao instrumento.

Ao se apresentarem de forma verticalizada e meritocrática, as avaliações externas caminham em direção a um Estado mais regulador e fiscalizador. Com frequência, parafraseando Freitas et al. (2012), esses exames têm se apresentado como se fosse o produto final do trabalho desenvolvido pelo professor e pelo aluno, passando a ser visto como uma categoria que modula os objetivos, os conteúdos, os métodos e a própria avaliação interna, convertendo o ensino em preparação para provas, negando a sua qualidade.

Esses exames podem fornecer importantes informações sobre o progresso das escolas, entretanto não devem ser utilizadas como o único dado a partir do qual decisões importantes são tomadas. As informações produzidas pelos exames externos precisam se articular com a avaliação institucional da escola e a avaliação $\mathrm{da} /$ para as aprendizagens desenvolvidas pelo professor em sala de aula.

Existia, na UE pesquisada, a preocupação em melhorar os resultados, entretanto, por parte das alfabetizadoras, era fundamental uma análise mais pedagógica dos resultados aferidos pela ANA, visto que esse encaminhamento contribuiria para um melhor planejamento das aulas, logo, para o avanço das aprendizagens dos estudantes. Por outro lado, para a equipe gestora ficou evidente a preocupação em elevar os índices. Ao não esclarecer como acompanhava o planejamento das docentes e o desenvolvimento dos estudantes, os gestores pareciam, apenas, controlar o trabalho delas.

Ao examinar essa política de avaliação, centrada nos resultados, outra política é posta em prática, a de responsabilização. Os professores são os mais atingidos, os primeiros a serem responsabilizados pelo fracasso dos estudantes que não conseguiram atingir o resultado desejado. Para Freitas (2012), por trás 
dessa política, existem: os testes, a divulgação dos resultados e o sistema de recompensas/punições.

A responsabilização pode gerar descontentamento do professor com o próprio desempenho e, ao mesmo tempo, a aceitação, a acomodação e a luta por alcançar o estipulado como índice. Ao reforçar a eficiência e eficácia com metas de desempenho prefixadas, a gestão por resultados exige maior obrigação das escolas com os exames nacionais. Precisamos refletir sobre as políticas de avaliação e as modificações que têm provocado na natureza do trabalho escolar, o que pode levar ao adoecimento dos trabalhadores por se sentirem cobrados pelos resultados, sem, no entanto, serem oferecidas condições objetivas de trabalho, o que contribui para a intensificação e a precarização do trabalho docente.

De acordo com Ravitch (2011), precisamos defender um sistema de responsabilização que avalie as escolas com objetivo de ajudá-las, de fato, a melhorarem. O sistema de avaliação de alunos e, por consequência, dos professores, deveria ser mais amplo que medidas de desempenho em testes padronizados.

Em síntese, para que a escola possa cumprir sua função social, de socialização de saberes e produção de conhecimentos, os docentes precisam, no processo formativo, ser ouvidos nas suas escolhas didáticas em sala de aula. Esse processo é caracterizado por uma gestão do ensino e da aprendizagem ancorada no debate, na mediação das aprendizagens e por meio da intervenção crítica, tudo isso com o intuito de construir uma escola democrática e de qualidade para todos.

\section{REFERÊNCIAS}

ADRIÃO, Theresa; BORGHI, Raquel. Organização do trabalho escolar e exclusão educacional: caminhos, desafios e possibilidades. In: CORREA, B. C.; GARCIA, T. O. (Org.). Políticas educacionais e organização do trabalho na escola. São Paulo: Xamã, 2008.

ARAÚJO, Ivanildo Amaro de. Escolas visíveis ou invisíveis? Sentidos e efeitos das avaliações externas no contexto escolar. In: ENDIPE, 16. Anais [...] Campinas, SP: Unicamp 2012. p. 01-15.

ARROYO, Miguel Gonzáles. Ciclos de desenvolvimento humano e formação de professores. Educação e Sociedade, Campinas, SP, ano XX, n. 68, p. 143-62, dez. 1999.

BONDIOLI, Anna. O projeto pedagógico da creche e a sua avaliação: a qualidade negociada. Campinas, SP: Autores Associados, 2004. 
Avaliação Nacional da Alfabetização no contexto escolar: um olhar para as concepções docentes e da gestão educacional

BRASIL. MEC anuncia Política Nacional de Alfabetização para reverter quadro de estagnação na aprendizagem. INEP, 2017a. Disponível em: http://portal.inep.gov.br/ artigo/-/asset_publisher/B4AQV9zFY7Bv/content/mec-anuncia-politica-nacional-dealfabetizacao-para-reverter-quadro-de-estagnacao-na-aprendizagem/21206. Acesso em: 7 nov. 2017.

BRASIL. Ministério da Educação - MEC. Secretaria de Educação Básica. Base Nacional Comum Curricular. Educação é a Base. Ensino Fundamental. Brasília, dez. 2017b.

BRASIL. Instituto Nacional de Estudos e Pesquisas Educacionais Anísio Teixeira (Inep). Avaliação Nacional da Alfabetização (ANA): documento básico. Brasília: INEP, 2013.

BRASIL. MEC. Portaria n. 867, de 4 de julho de 2012. Institui o Pacto Nacional pela Alfabetização na Idade Certa e as ações do Pacto e define suas diretrizes gerais. Brasília, 2012.

BRASIL. Ministério da Educação. Secretaria de Educação Básica. Diretoria de Currículos e Educação Integral. Coordenação Geral de Ensino Fundamental. Programa Mais Alfabetização. Manual Operacional do Sistema de Orientação Pedagógica e Monitoramento. Brasília, abril 2018.

DISTRITO FEDERAL. Diretrizes de Avaliação Educacional: aprendizagem, institucional e em larga escala. Brasília: SEEDF, 2014-2016.

DISTRITO FEDERAL. Diretrizes Pedagógicas para Organização Escolar do 2ํ Ciclo para as aprendizagens: BIA e 2oㅡoco. Brasília: SEEDF, 2014.

FREITAS, Luiz Carlos de. A organização do trabalho pedagógico no contexto atual do ensino público brasileiro. Entrevista. Crítica Educativa, Sorocaba, SP, v. 2, n. 1, p. 202-26, jan./jun. 2016.

FREITAS, Luiz Carlos de. Os reformadores empresariais da educação: da desmoralização do magistério à destruição do sistema público de educação. Educação e Sociedade, Campinas, SP, v. 33, n. 119, p. 379-404, 2012.

FREITAS, Luiz Carlos de. Eliminação adiada: o ocaso das classes populares no interior da escola e a ocultação da (má) qualidade do ensino. Educação \& Sociedade, Campinas, SP, v. 28, n. 100, Especial, p. 965-87, out. 2007.

FREITAS, Luiz Carlos de. Crítica da organização do trabalho pedagógico e da didática. 7. ed. Campinas, SP: Papirus, 2005a. 
FREITAS, Luiz Carlos de. Qualidade negociada: avaliação e contra regulação na escola pública. Educação Sociedade, Campinas, SP, v. 26, n. 92, p. 911-33, Especial, out. 2005b. Disponível em: http://www.scielo.br/scielo.php?pid=S0101-73302005000300010\&script= sci_abstract\&tlng=pt

FREITAS, Luiz Carlos de et al. Avaliação e políticas públicas educacionais: ensaios contraregulatórios em debate. Campinas: Leitura Crítica, 2012a.

GATTI, Bernadete Angelina. Políticas de avaliação em larga escala e a questão da inovação educacional. Série-Estudos, Campo Grande, MS, n. 33, p. 29-37, jan./jul. 2012.

GIL, Antonio Carlos. Métodos e técnicas de pesquisa social. 5. ed. São Paulo: Atlas, 1999.

HYPOLITO, Álvaro Moreira. Processo de trabalho na escola: algumas categorias para análise. Teoria \& Educação, Porto Alegre, RS, n. 4, p. 3-21, 1991.

LUCKESI, Cipriano Carlos. Avaliação da aprendizagem: componente do ato pedagógico. São Paulo: Cortez, 2011.

LÜDKE, Menga. Evoluções em avaliação. In: FRANCO, C. (Org.). Avaliação, ciclos e promoção na educação. Porto Alegre: Artmed, 2001.

MAGALHÃES, Priscila Maria Vieira dos Santos. As artes de fazer da avaliação fabricadas no cotidiano escolar: um olhar para as táticas avaliativas dos professores dos anos iniciais do Ensino Fundamental. 2018. Dissertação (Mestrado em Educação Contemporânea) Universidade Federal de Pernambuco, Caruaru, PE, 2018.

MAGALHÃES, Priscila Maria Vieira dos Santos; GONÇALVES, Crislainy; ALMEIDA, Lucinalva de; OLIVEIRA-MENDES, Solange Alves de. Dos discursos aos sentidos: as práticas avaliativas de professores dos anos iniciais do Ensino Fundamental. Revista Eletrônica de Educação, São Carlos, SP, v. 12, n. 1, p. 90-103, jan./abr. 2018.

MAINARDES, Jefferson. A escola em ciclos: fundamentos e debates. São Paulo: Cortez, 2009. (Coleção Questões de Nossa Época).

MARX, Karl. Os manuscritos econômicos e filosóficos. Lisboa: Edições 70, 1964.

OLIVEIRA, Solange Alves. Progressão das atividades de Língua Portuguesa e o tratamento dado à heterogeneidade das aprendizagens: um estudo da prática docente no contexto dos ciclos. 2010. Tese (Doutorado em Educação)- Universidade Federal de Pernambuco, Recife, 2010. 
PARO, Vitor Henrique. Gestão democrática da escola pública. 3 ed. São Paulo: Ática, 2008.

PEREIRA, Maria Susley. Progressão continuada no Bloco Inicial de Alfabetização: por uma escola diferente da que conhecemos. Revista Com Censo, Brasília, Edição Especial, n. 3, p. 33-40, dez. 2015.

RAVITCH, Diane. Vida e morte do grande Sistema Escolar Americano. Como os testes padronizados e o modelo de mercado ameaçam a educação. Porto Alegre: Sulina, 2011.

VÁZQUEZ, Adolfo Sánchez. Filosofia da práxis. Rio de Janeiro: Paz e Terra, 1968.

VILLAS BOAS, Benigna Maria de Freitas. A avaliação na escola em ciclos. Brasília, DF: Grupo de Estudos e Pesquisa em Avaliação e Organização do Trabalho Pedagógico- GEPA, 2013. Disponível em: http://gepa-avaliacaoeducacional.com.br/avaliacao-na-escola-em-ciclos/. Acesso em: 12 out. 2017.

VILLAS BOAS, Benigna Maria de Freitas. Projeto de intervenção na escola: mantendo as aprendizagens em dia. Campinas, SP: Papirus, 2010.

\section{Sobre as autoras:}

Márcia Vânia Silvério Perfeito: Especialista em Supervisão e Administração Escolar e em Didática Fundamentos Teóricos da Prática Pedagógica. Graduada em Pedagogia, com habilitação em supervisão escolar, didática, fundamentos da educação, estrutura e funcionamento do ensino, pelo Centro Universitário de Caratinga e inspeção escolar, pela Univale. Professora pela Secretaria de Educação do Distrito Federal / articuladora do Centro de Referência para os Anos Iniciais (CRAI), Secretaria de Educação do Distrito Federal. Tem experiência na área de Educação, com ênfase em Atividades Anos Iniciais. E-mail: mvsperfeito@gmail.com, Orcid: http://orcid.org/0000-0002-3496-9405

Solange Alves de Oliveira-Mendes: Doutora em Educação pela Universidade Federal de Pernambuco (UFPE), em articulação com o Institut National de Recherche Pédagogique, através do doutorado sanduíche. Mestre em Educação e graduada em Pedagogia pela UFPE. Atua na área de Língua Materna, Alfabetização e Literatura (FE-UnB) e no Programa de Pós-Graduação em Educação da Faculdade de Educação da UnB - Mestrado Acadêmico na linha de pesquisa EAPS: Escola, 
Aprendizagem, Ação Pedagógica e Subjetividade na Educação - Letramento e Formação de Professores. E-mail: solangealvesdeoliveira@gmail.com, Orcid: http://orcid.org/0000-0001-9864-5314

Lucinalva Andrade Ataíde de Almeida: Doutora em Educação pela Universidade Federal de Pernambuco (UFPE). Orienta estudos sobre políticas curriculares, currículo e formação de professores, com ênfase na Educação Básica e no curso de Pedagogia. E-mail: nina.ataide@gmail.com, Orcid: http://orcid.org/0000-0002-3577-1716

Recebido em abril de 2018

Aprovado em maio de 2019 